Corresponding authors: geere@ mskcc.org; rong.chen@mssm. edu

(C) 2017 Uzilov et al. This article is distributed under the terms of the Creative Commons Attribution License, which permits unrestricted reuse and redistribution provided that the original author and source are credited.

Ontology terms:

adrenocorticotropic hormone excess; increased circulating ACTH level; increased circulating cortisol level; neoplasm of the anterior pituitary; neoplasm of the endocrine system; pituitary corticotropic cell adenoma

Published by Cold Spring Harbor Laboratory Press

doi: $10.1101 / \mathrm{mcs} . a 001602$

\section{Identification of a novel RASD1 somatic mutation in a USP8-mutated corticotroph adenoma}

\author{
Andrew V. Uzilov, ${ }^{1}$ Khadeen C. Cheesman, ${ }^{2,7}$ Marc Y. Fink, ${ }^{1,7}$ Leah C. Newman, ${ }^{1}$ \\ Chetanya Pandya, ${ }^{1}$ Yelena Lalazar, ${ }^{2}$ Marco Hefti, ${ }^{3}$ Mary Fowkes, ${ }^{3}$ Gintaras Deikus, ${ }^{1}$ \\ Chun Yee Lau, ${ }^{1}$ Aye S. Moe, ${ }^{1}$ Yayoi Kinoshita, ${ }^{3}$ Yumi Kasai, ${ }^{1,6}$ Micol Zweig, ${ }^{1}$ \\ Arpeta Gupta, ${ }^{2}$ Daniela Starcevic, ${ }^{1}$ Milind Mahajan, ${ }^{1}$ Eric E. Schadt, ${ }^{1}$ Kalmon \\ D. Post, ${ }^{4}$ Michael J. Donovan, ${ }^{3}$ Robert Sebra, ${ }^{1}$ Rong Chen, ${ }^{1}$ and Eliza B. Geer ${ }^{2,4,5}$ \\ ${ }^{1}$ Department of Genetics and Genomic Sciences and Icahn Institute for Genomics and Multiscale Biology, \\ Icahn School of Medicine at Mount Sinai, New York, New York 10029, USA; ${ }^{2}$ Division of Endocrinology, \\ Diabetes, and Bone Disease, Department of Medicine, Icahn School of Medicine at Mount Sinai, New York, \\ New York 10029, USA; ${ }^{3}$ Department of Pathology, Icahn School of Medicine at Mount Sinai, New York, \\ New York 10029, USA; ${ }^{4}$ Department of Neurosurgery, Icahn School of Medicine at Mount Sinai, New York, \\ New York 10029, USA; ${ }^{5}$ Multidisciplinary Pituitary and Skull Base Tumor Center, Memorial Sloan \\ Kettering, New York, New York 10065, USA
}

Abstract Cushing's disease (CD) is caused by pituitary corticotroph adenomas that secrete excess adrenocorticotropic hormone (ACTH). In these tumors, somatic mutations in the gene USP8 have been identified as recurrent and pathogenic and are the sole known molecular driver for CD. Although other somatic mutations were reported in these studies, their contribution to the pathogenesis of CD remains unexplored. No molecular drivers have been established for a large proportion of CD cases and tumor heterogeneity has not yet been investigated using genomics methods. Also, even in USP8-mutant tumors, a possibility may exist of additional contributing mutations, following a paradigm from other neoplasm types where multiple somatic alterations contribute to neoplastic transformation. The current study utilizes whole-exome discovery sequencing on the Illumina platform, followed by targeted amplicon-validation sequencing on the Pacific Biosciences platform, to interrogate the somatic mutation landscape in a corticotroph adenoma resected from a CD patient. In this USP8-mutated tumor, we identified an interesting somatic mutation in the gene RASD1, which is a component of the corticotropin-releasing hormone receptor signaling system. This finding may provide insight into a novel mechanism involving loss of feedback control to the corticotropinreleasing hormone receptor and subsequent deregulation of ACTH production in corticotroph tumors.

[Supplemental material is available for this article.]

\section{INTRODUCTION}

Cushing's syndrome is caused by chronic exposure to elevated glucocorticoids via exogenous and endogenous sources. The typical clinical features of Cushing's syndrome are

6Present address: New York Genome Center, New York, New York 10013, USA

${ }^{7}$ These authors contributed equally to this work. 
related to hypercortolism and include accumulation of central fat, moon facies, neuromuscular weakness, osteoporosis or bone fractures, metabolic complications, and mood changes. It is associated with increased morbidity and mortality especially due to cardiovascular disease (Lacroix et al. 2015; Sharma et al. 2015). Adrenocorticotropic hormone (ACTH)-dependent Cushing's accounts for $80 \%$ of endogenous cases, and among these, pituitary corticotroph adenomas are the most common cause (Lacroix et al. 2015). This is known as Cushing's disease (CD). Corticotroph adenomas account for $\sim 10 \%$ of pituitary adenomas and the vast majority of them are benign. The incidence of $C D$ ranges from 1.2 to 2.4 per million population per year in Europe and up to 8 per million population per year in the United States (Etxabe and Vazquez 1994; Lindholm et al. 2001; Feelders et al. 2012; Broder et al. 2015).

Genetic factors involved in corticotroph tumorigenesis are largely unknown. ACTHsecreting adenomas due to germline mutations can rarely arise in the context of familial disorders, such as multiple endocrine neoplasia type 1 (MEN1), familial isolated pituitary adenomas (associated with aryl-hydrocarbon receptor-interacting protein [gene AIP] mutations), and MEN4 (associated with cyclin-dependent kinase inhibitors) (Dworakowska and Grossman 2012; Perez-Rivas and Reincke 2016). Rare somatic mutations in the TP53 gene (Kawashima et al. 2009) and in the glucocorticoid receptor (gene NR3C1) and related proteins have also been reported (Lacroix et al. 2015; Ma et al. 2015; Reincke et al. 2015).

The identification of recurrent somatic mutations that lead to $C D$ has been elusive until the recent discovery of somatic mutations in the ubiquitin-specific peptidase 8 gene (USP8) in 35\%-62\% of CD-causing corticotroph adenomas (Perez-Rivas and Reincke 2016). The USP8 gene encodes an enzyme with deubiquitinase activity. To date, 22 different USP8 mutations have been identified in $129 \mathrm{ACTH}$-secreting adenomas from 271 patients across three studies (Ma et al. 2015; Perez-Rivas et al. 2015; Reincke et al. 2015; for review, see Perez-Rivas and Reincke 2016), with confirmation of USP8 mutation prevalence in later studies (Hayashi et al. 2016; Song et al. 2016). All of these mutations were located in exon 14 in a mutation hotspot region that overlaps with the sequence that codes for the 14-3-3 binding motif, which is highly conserved among different species. This mutation constitutively activates USP8, leading to enhanced recycling of the epidermal growth factor receptor (gene EGFR) to the plasma membrane, resulting in sustained signaling and increased ACTH synthesis (Perez-Rivas and Reincke 2016).

The distinction between a tumor's monoclonal origin (in which all tumor cells are descendants of a single cell in which a driver mutation occurred) versus polyclonal origin (in which tumor cells are a mixture of multiple clonal expansions, possibly containing different driver mutations) is important to understanding the disease mechanism. The clonal origin of a tumor can be determined by X-Chromosome inactivation analysis in female patients with heterozygous alleles at various X-linked loci (Levy 2001). Previous studies using this class of techniques have shown that all (Biller et al. 1992; Gicquel et al. 1992) or most (Herman et al. 1990; Schulte et al. 1991) corticotroph adenomas are monoclonal. However, arguments for polyclonality in a nonnegligible fraction of corticotroph and other pituitary adenomas have been proposed (Clayton et al. 2000; Levy 2000, 2001; Clayton and Farrell 2001, 2004). Analysis of allelic fractions of somatic mutations and germline variants in tumor genomic sequencing data can potentially shed light on the genetic heterogeneity and clonal origin of corticotroph adenomas, but such analysis has not been carried out in previous studies where such data were available (Ma et al. 2015; Reincke et al. 2015).

Genome- and exome-wide analyses on DNA from tumors and patient-matched normal controls have been instrumental in identifying driver genes in many neoplasm types. In this study, we performed whole-exome sequencing (WES) on a tumor sample from a patient with $C D$ and on blood samples from the patient and her two healthy sisters (identical triplets; data from the two healthy sisters was not used in this case report). We have identified a novel 
mutation in the GTP-binding site of the gene RASD1 that we hypothesize contributes to the pathogenesis of CD in this patient because of the involvement of RASD1 in regulation of ACTH production by glucocorticoid feedback. Additionally, based on the allelic fractions of the mutations, these tumor cells exhibit either subclones or polyclonal origin. These findings challenge the current model that corticotroph adenomas are genetically homogeneous.

\section{RESULTS}

\section{Clinical Presentation and Family History}

A 32-year-old woman with no known family history of pituitary diseases, who was one of identical triplet sisters, presented with a history of recently diagnosed type 2 diabetes mellitus and weight gain, easy bruising, and subjective plethora. On review of systems she endorsed occasional acne, moodiness before her menstrual period, and chronic insomnia. She denied neuromuscular weakness, significant mood changes, difficulty concentrating, or hirsutism. Evaluation confirmed CD: 24-h urinary free cortisol (UFC) levels were 154 and $90.4 \mu \mathrm{g}(\mathrm{nl}<50 \mu \mathrm{g})$; midnight salivary cortisol (MSC) levels were 0.118, 0.142, and $0.917 \mu \mathrm{g} / \mathrm{dll}(\mathrm{nl}<0.112 \mu \mathrm{g} / \mathrm{dl})$; serum cortisol was $4.1 \mu \mathrm{g} / \mathrm{dl}$ after $8 \mathrm{mg}$ dexamethasone $(\mathrm{nl}<1.8 \mu \mathrm{g} / \mathrm{dl})$; random morning plasma ACTH level was $50 \mathrm{pg} / \mathrm{ml}$; and pituitary magnetic resonance imaging (MRI) showed a clearly defined right-sided 4-mm lesion (Fig. 1). She was also found to have dyslipidemia and fatty liver on MRI of the abdomen. She was diagnosed with CD and underwent transnasal transsphenoidal adenomectomy without complication. Immunohistochemistry confirmed a corticotroph adenoma (Fig. 2) with a low MIB-1 index. Pathologic examination of tissue slices estimated $40 \%-50 \%$ tumor cellularity.

\section{Genomic Analyses}

WES of the blood-derived normal DNA and formalin-fixed paraffin-embedded (FFPE)derived tumor DNA from the patient was carried out on the Illumina HiSeq 2500 platform, yielding a mean sequencing depth of $145 x$ and $315 x$, respectively, that was usable for variant calling (Table 1). Germline (constitutional) variants and somatic mutations were called; supporting binary alignment (BAM) read alignments for each somatic mutation

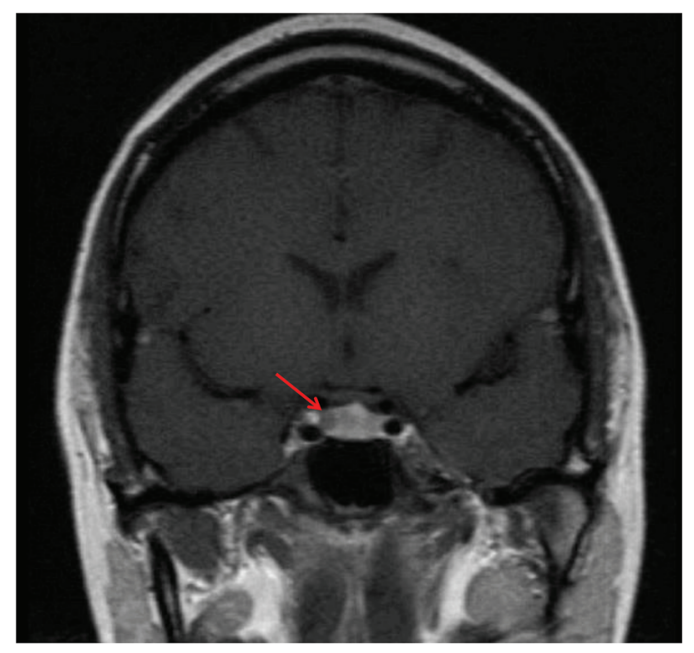

Figure 1. Pituitary magnetic resonance imaging (MRI) coronal image confirmed a right-sided sellar hypointensity consistent with a 4-mm pituitary adenoma. 

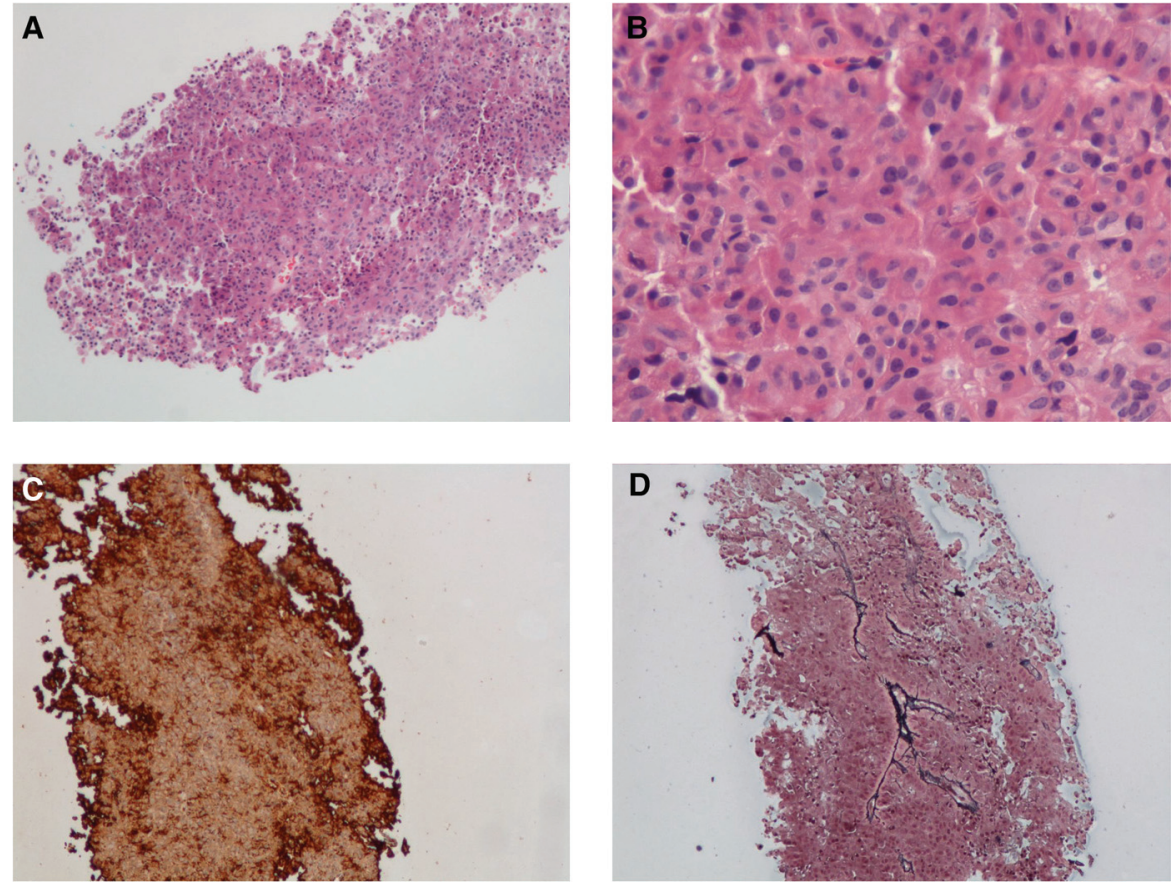

Figure 2. Histologic sections revealed a monotonous tumor composed of medium-sized cells with finely stippled chromatin $(A, B)$. Tumor cells were strongly positive for adenocorticotropic hormone $(A C T H)$ by immunohistochemistry $(C)$, whereas a reticulin stain $(D)$ showed effacement of the fibrovascular septae. (A) Hematoxylin and eosin (H\&E) 100x; (B) H\&E 400x; (C) ACTH immunostain, 100x; (D) reticulin, 100x.

were manually reviewed in Integrative Genomics Viewer (IGV) (Robinson et al. 2011; Thorvaldsdóttir et al. 2013), yielding 36 passing calls whose class, type, and trinucleotide context are depicted in Figure 3 (the variant genomic coordinates are provided as Supplemental File 1). C>T transitions were the most common single-nucleotide variant (SNV) type, as is common in many cancer mutation signatures (Alexandrov et al. 2013); although importantly Alexandrov et al. (2013) did not include mutations outside protein-coding exons, which are included in Fig. 3. Notably, the mutations were dominated by deletions, only two of which were in protein-coding regions. No insertions were observed (Table 2).

Table 1. Sequencing and alignment statistics for Illumina whole-exome sequencing (WES) of the patient's normal/tumor pair

\begin{tabular}{lccccc}
\hline Sumber of clusters & $\begin{array}{c}\text { yielding "pass filter" } \\
\text { read pairs } \\
\text { (PF_READS/2) }\end{array}$ & $\begin{array}{c}\text { Mean usable } \\
\text { sequencing } \\
\text { depth }\end{array}$ & $\begin{array}{c}\text { Percent target } \\
\text { bases with }>30 \times \\
\text { usable sequencing } \\
\text { depth }\end{array}$ & $\begin{array}{c}\text { Percent usable bases out of } \\
\text { all "pass filter" read bases } \\
\text { (PCT_USABLE_BASES_ } \\
\text { ON_TARGET) }\end{array}$ & $\begin{array}{c}\text { Percent duplication } \\
\text { (PERCENT_DUPLICATION) }\end{array}$ \\
\hline Normal & $77 \times 10^{6}$ & $145 \times$ & 96 & 74 & 10 \\
Tumor & $335 \times 10^{6}$ & $315 \times$ & 98 & 37 & 54 \\
\hline
\end{tabular}

Data as given by the Genome Analysis Toolkit (GATK) v3.2 (McKenna et al. 2010; DePristo et al. 2011; Van der Auwera et al. 2013) and Picard (http:// broadinstitute.github.io/picard) pipelines.

Picard terminology is as defined on https://broadinstitute.github.io/picard/picard-metric-definitions.html, with the Picard output field name given in parentheses. "Duplication" includes both optical/sequencing and polymerase chain reaction (PCR) duplicates according to Picard and is computed on the entire genome (i.e., not just in exome target regions). "Usable" read bases are bases aligned to exome-target regions and not in duplicate reads. 


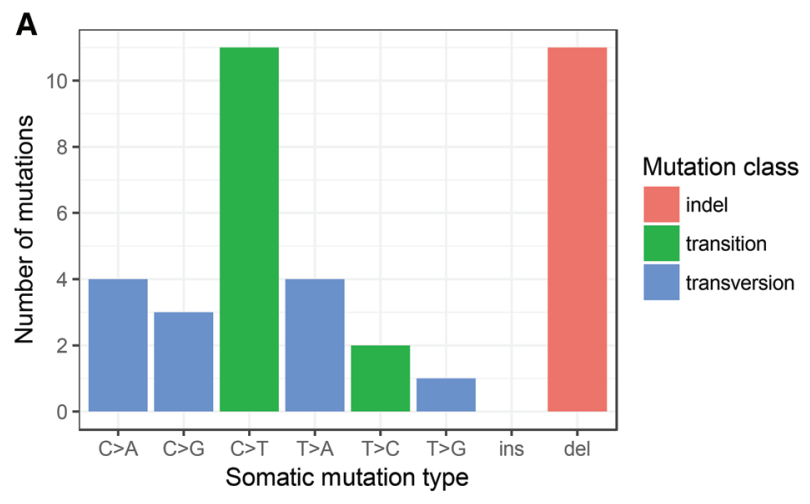

B

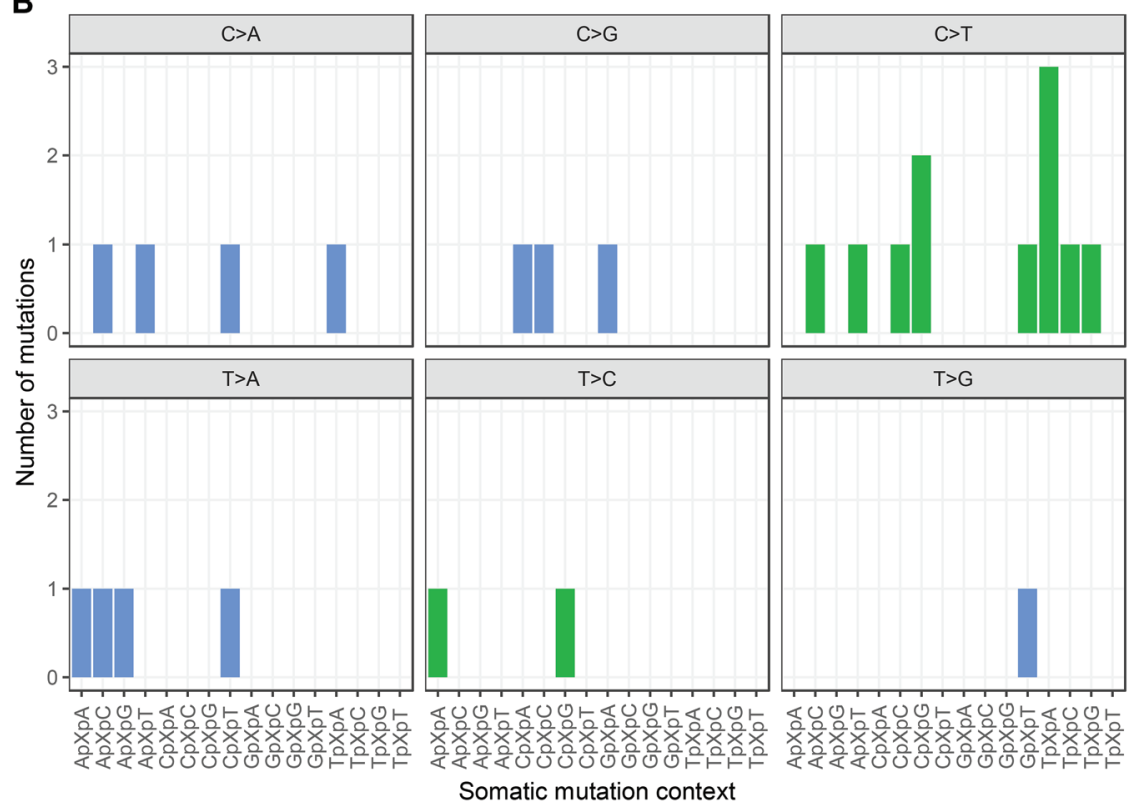

Figure 3. (A) Distribution of the 36 somatic mutation calls passing manual review by type and class. All passing calls were included regardless of predicted impact (i.e., synonymous, intronic, and intergenic calls are included). For single-nucleotide variants (SNVs), type is given by the pyrimidine of the mutated base pair as per previous conventions (Alexandrov et al. 2013). (B) SNVs from A were further categorized into 96 trinucleotide classes defined by the immediately flanking bases (as previously described in Alexandrov et al. 2013).

After variant annotation, 13 of 36 somatic mutation calls were predicted to alter the amino acid sequence of a protein isoform (Table 2). This count of 13 protein-altering mutations is consistent with the low counts previously reported in other WES studies of corticotroph adenomas: median 7, range 3-23 (Reincke et al. 2015) and median 5, range 1-9 (Ma et al. 2015). The difference with Ma et al. (2015) can be explained by the higher sequencing depth in our study and differences in variant-calling procedure described in Ma et al. (2015); calls with allelic fraction of $<20 \%$ were discarded, which would have eliminated most of our calls (Table 2). Validation was carried out on 12 of the 13 mutations via targeted amplicon sequencing on a second next-generation sequencing (NGS) platform (Pacific Biosciences RSII, PacBio), confirming 100\% of the attempted mutations as somatic (present in tumor, absent in normal) and also obtaining similar allelic fractions to the original Illumina-based calls. Following the heuristic from Alexandrov et al. (2013) that WES 


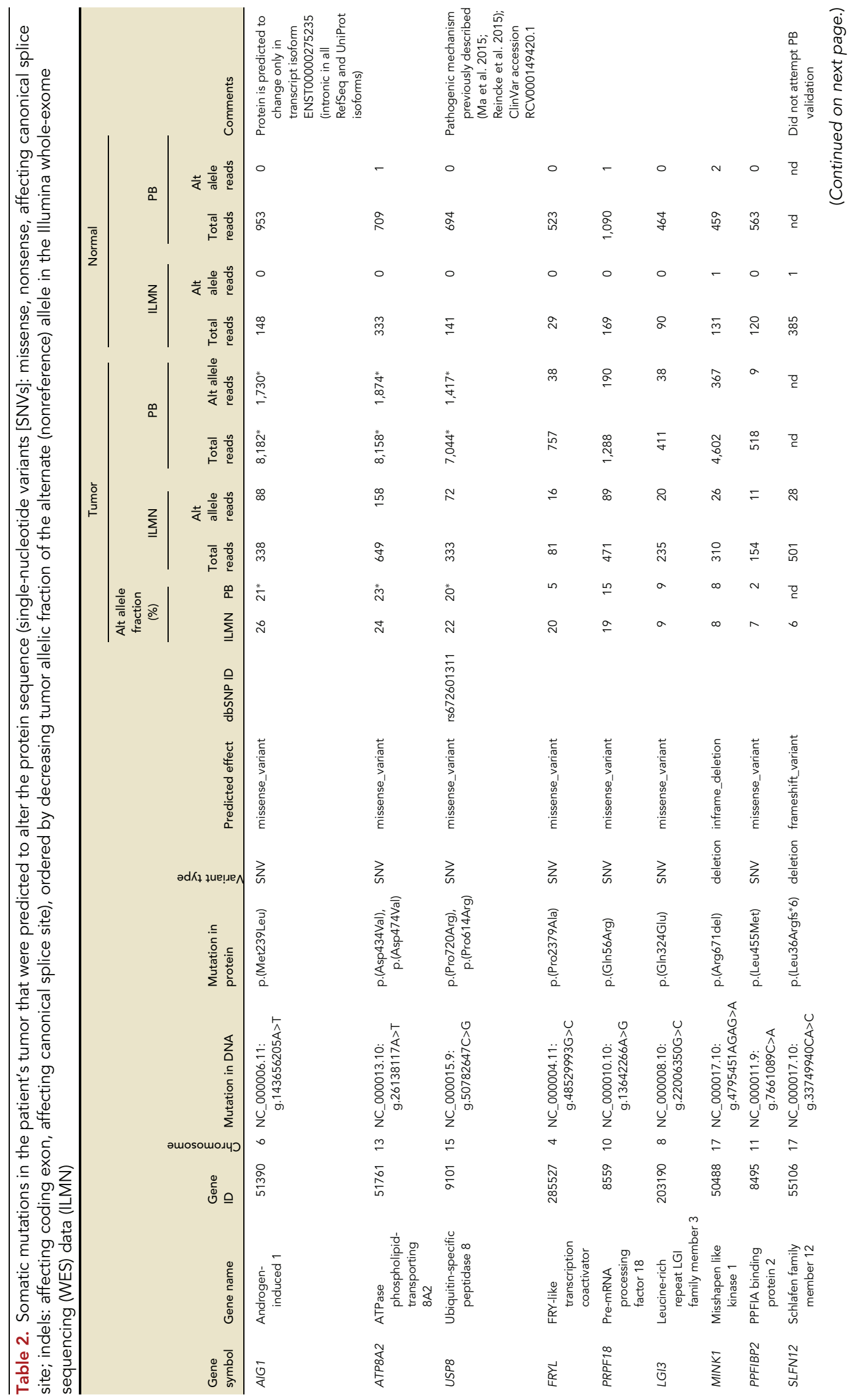




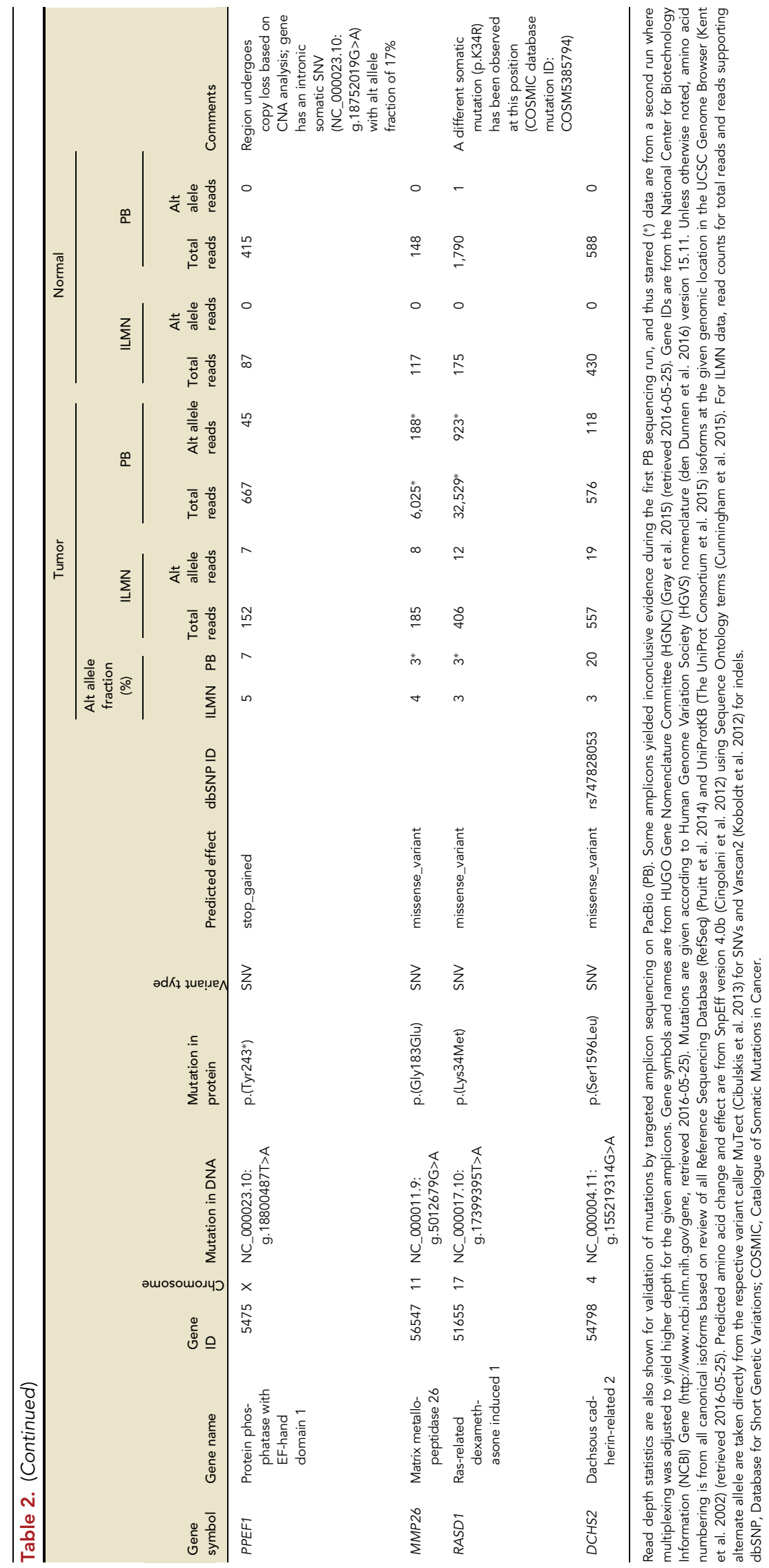


interrogates $\sim 30$ megabases $(\mathrm{Mb})$ of protein-coding exons in the human genome, we obtained a somatic mutation rate of 0.43 mutations/Mb for protein-altering mutations and 0.53 mutations/Mb for mutations in coding exons (13 protein-altering; three synonymous). When the latter is compared with somatic mutation rates across many cancer types in Alexandrov et al. (2013), the somatic mutation rate in our patient was low, a finding consistent with previous WES studies of corticotroph adenomas (Ma et al. 2015; Reincke et al. 2015).

The allelic fractions of somatic mutations ranged from $3 \%$ to $26 \%$. Under the hypothesis that one of these mutations initiates or precedes neoplastic transformation of a single cell that then undergoes clonal expansion, the tumor purity of the sequenced specimen may therefore be $<52 \%$, consistent with the estimate of $40 \%-50 \%$ from pathologic examination. Although the presence of copy-number alterations (CNAs) can confound such an estimate, we did not observe aneuploidy or CNA events that confound the allelic fractions in Table 2 (using the SAAS-CNV tool [Zhang and Hao 2015] as before [Uzilov et al. 2016]; data not shown).

We cross-referenced our somatic mutation calls with the Catalogue of Somatic Mutations in Cancer (COSMIC) database (Forbes et al. 2015) to determine whether any had previously been observed in a tumor; no exact matches were found and one approximate match is noted in Table 2. We also cross-referenced these calls with ClinVar (Landrum et al. 2016), as some variants are known to occur as both somatic driver mutations and germline variants in inherited/familial neoplasm syndromes. We then reviewed the gene annotations in the list of 13 protein-altering mutations in the context of potential involvement in the molecular pathways implicated in CD or in corticotroph tissues in general. Notably, our patient's adenoma had the USP8 p.P720R mutation that has previously been described as involved in the pathogenesis of CD (Ma et al. 2015; Reincke et al. 2015), occurring in 35\%-62\% of CD-causing corticotroph adenomas (Perez-Rivas and Reincke 2016); this was also the sole mutation identified in the ClinVar cross-reference. The high allelic fraction of this mutation (20\%-22\%, depending on sequencing platform; third highest on the list) is consistent with the hypothesis that it is a driver mutation present early in the clonal expansion of the tumor.

A novel mutation, p.K34M, in the GTP-binding region of RASD1 was identified in this tumor, at an allelic fraction (3\%) indicative of a subclone with respect to cells containing USP8 p.P720R. RASD1 was originally discovered as an inducible gene in dexamethasone-stimulated AtT-20 mouse corticotroph cells (Kemppainen 1998). Based on this connection to the cell type under study, further computational analysis of the functional significance of this mutation was conducted. Alignment of several related small GTPases, including the well-studied oncogenes KRAS, NRAS, and HRAS, revealed that p.K34M is found within the G1 motif and is likely involved in binding to GTP (Fig. 4). However, the precise contacts between the enzyme and substrate are not clear given that the $\mathrm{G} 1$ motif diverges in the RASD family from the other small GTPases for which substrate-bound crystal structures are available. Other genes in Table 2 were reviewed for possible connections to CD or corticotroph biology but were not judged to have a direct connection like USP8 or RASD1; hence, these two genes are the focus of this report.

\section{Treatment Outcomes}

Consistent with successful removal of the patient's ACTH-secreting tumor, her postoperative day 1 serum cortisol level was $3.4 \mu \mathrm{g} / \mathrm{dl}$. She was discharged on physiologic oral hydrocortisone replacement and subsequently tapered off after 4 mo. Following discontinuation of oral hydrocortisone, UFC, 8 mg dexamethasone suppressed serum cortisol, and MSC concentrations were all within the normal range, consistent with $C D$ remission. $C D$ symptoms 


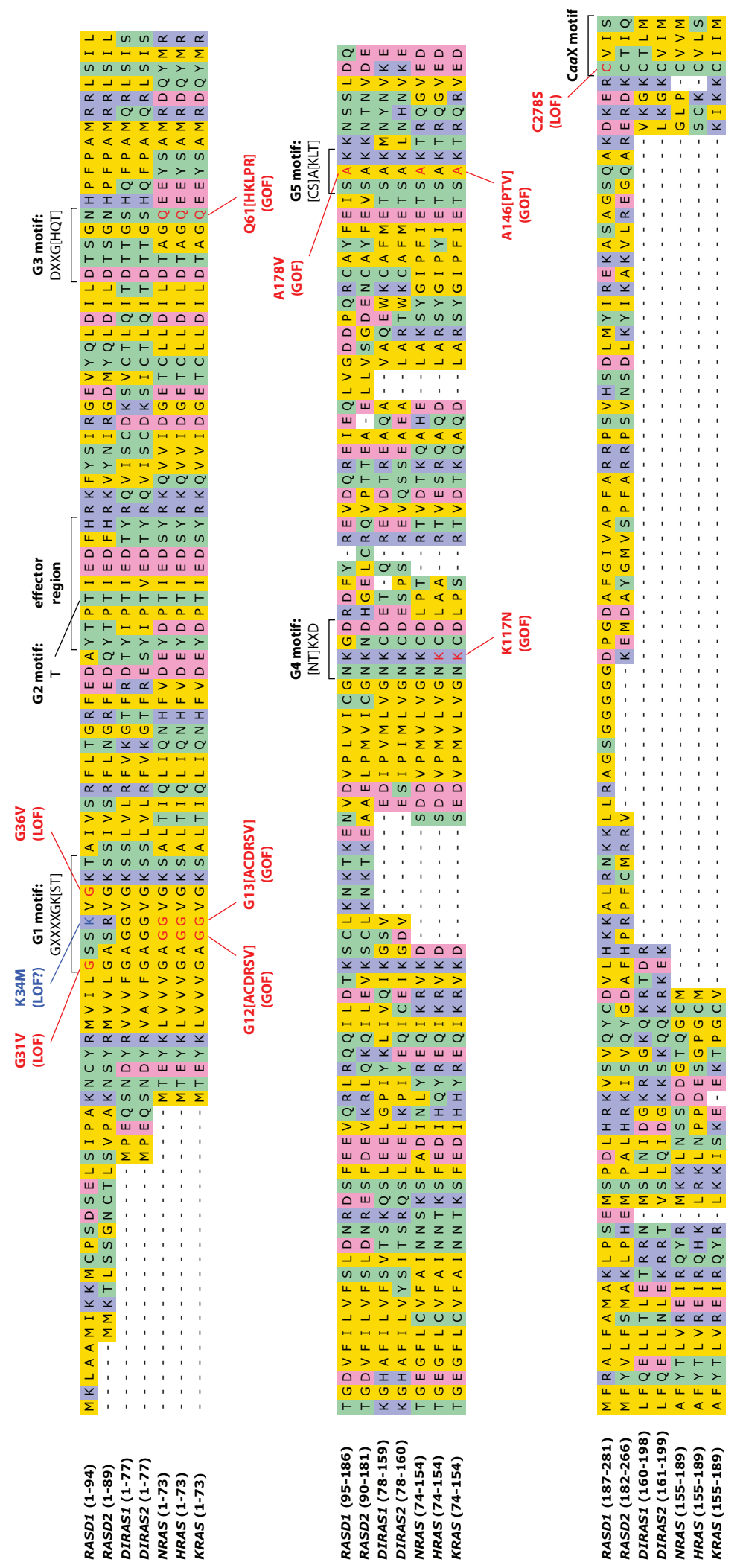

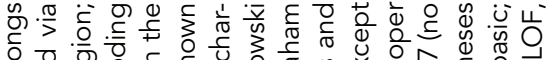

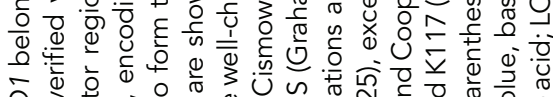

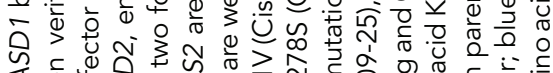

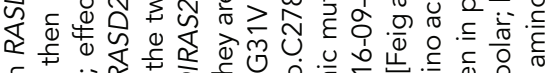

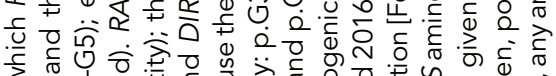

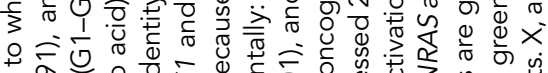

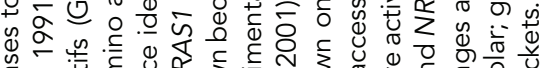

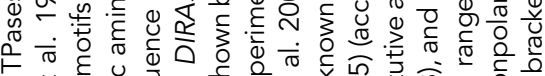
更

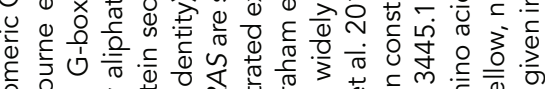

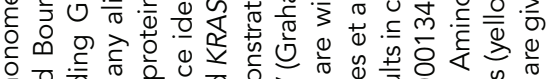

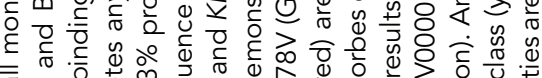

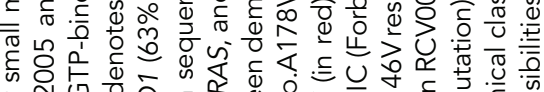

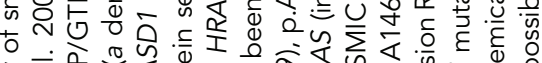

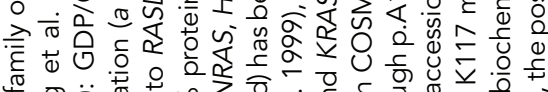

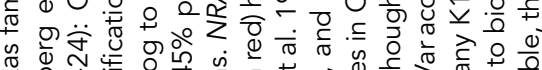

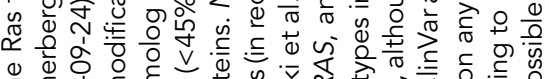

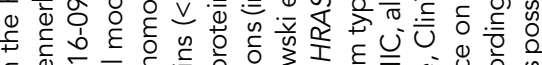

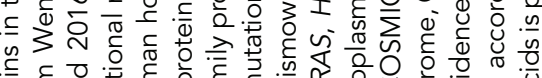

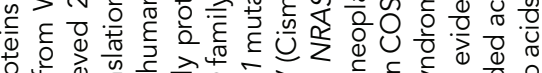

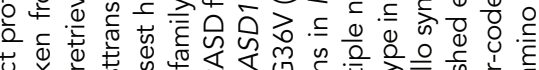

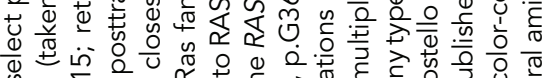

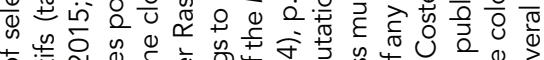

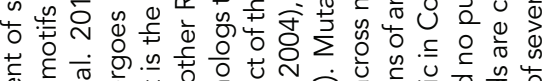

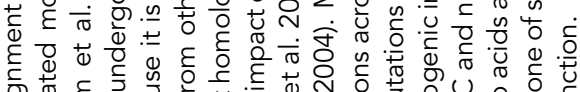

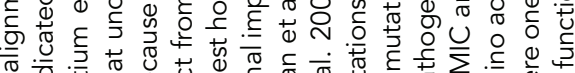

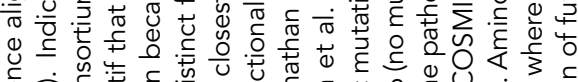

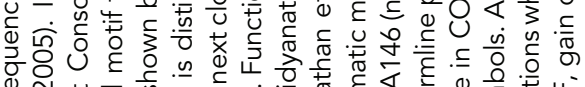

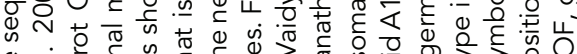

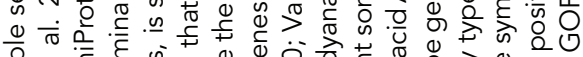

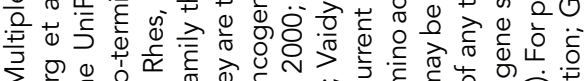

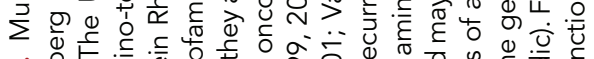

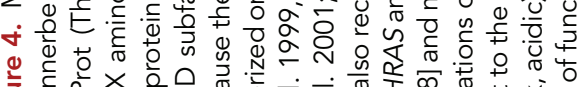

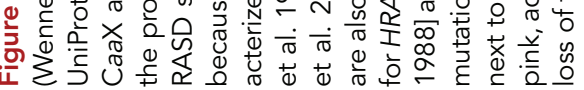


and comorbidities, including blood glucose levels, also improved. She remains in remission $3.3 \mathrm{yr}$ after surgery.

\section{DISCUSSION}

\section{Tumor Genetic Heterogeneity Models}

The current case identifies a novel RASD1 mutation in a USP8-positive corticotroph adenoma. The different allelic fractions between the USP8 and RASD1 somatic mutations in the studied tumor cells suggest that this ACTH-secreting tumor is genetically heterogeneous. Two models for heterogeneity are proposed as follows. In model A (Fig. 5A), the USP8 and RASD1 mutations may be synergistic, with the USP8 mutation occurring early in tumorigenesis, leading to abnormal proliferation of ACTH-secreting cells. At a later time point in the pathogenesis of the tumor, one of these USP8-mutant cells acquires a RASD1 mutation, resulting in a subclone of RASD1-mutant/USP8-mutant cells. In model B (Fig. 5B), the USP8 and RASD1 mutations are mutually exclusive, giving rise to subclones of cells with different mutation combinations (i.e., USP8-mutant/RASD1-wild type vs. USP8-wild type/RASD1-mutant). In both models, the tumor is genetically heterogeneous. Our hypothesis is that under both these models, RASD1 is a contributor to cell proliferation and ACTH secretion, but occurs in a small subpopulation of the tumor cells. Although these findings do not clearly distinguish between monoclonal versus polyclonal origin of the tumor, they nevertheless indicate that the tumor is genetically heterogeneous and suggest further studies into the interplay between multiple possible drivers.

\section{Rationale for RASD1 as a Contributor to Pathogenesis}

This study identified a mutation in RASD1 that may alter binding to GTP on the basis of RASD1 structural homology with well-studied, oncogenic small GTPases KRAS, NRAS, and HRAS. It is appealing to speculate that RASD1 p.K34M will have a reduced affinity to GTP and will therefore be less active (decreased capacity to interact with downstream proteins) versus wild type. However, because of the low allelic fraction (presumed subclonal nature) of this mutation, we cannot conclusively determine whether the mutation is homozygous or heterozygous. Several studies have defined a role for RASD1 in inhibition of $\mathrm{Ga}_{\mathrm{s}}$ signaling (Graham et al. 2001, 2004). This may occur through an interaction with $\mathrm{Ga}_{\mathrm{i}}$ (Cismowski et al. 2000). Normal feedback regulation within the hypothalamic-pituitary-adrenal axis
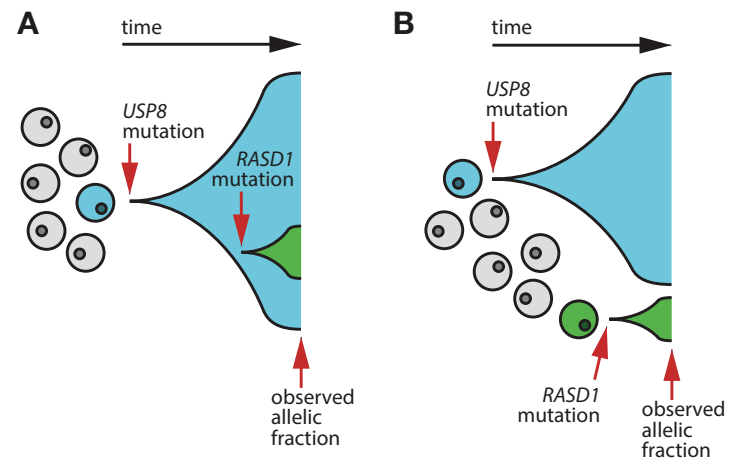

Figure 5. Two models that explain the observed allelic fractions of the USP8 and RASD1 somatic mutations. (A) Mutation RASD1 p.K34M occurs in a single cell derived from the clonal expansion of USP8-mutant cells. (B) Mutation RASD1 p.K34M occurs in an independent, USP8-wild-type cell and undergoes clonal expansion separate from the USP8-mutant clonal expansion. 
involves glucocorticoid induction of genes associated with suppression of corticotropinreleasing hormone receptor (CRHR) signaling. RASD1 was identified by its virtue of being strongly induced by dexamethasone in mouse corticotroph cell lines and pituitaries (Kemppainen 1998; Tu and Wu 1999; Brogan et al. 2001). Taken together, RASD1 may be a transcriptionally inducible negative regulator of $\mathrm{CRHR}-\mathrm{Ga}_{\mathrm{s}}$ signaling in corticotrophs. In cells with nonfunctional RASD1, this loop is no longer intact and CRHR signaling may become insensitive to negative feedback from glucocorticoids, thereby allowing for continued ACTH secretion. This alteration within corticotroph signaling and regulation may occur within the population of USP8 mutant cells or in a separate subclone. Separate molecular signaling schemes for these situations are depicted in Figure 6, illustrating the effect on the promoter of the gene POMC (whose protein product is processed to become ACTH, which is then secreted). It is intriguing to consider the possibility that loss of RASD1 function and mutation of USP8 may be additive or synergistic in relation to the pathophysiology of CD (Fig. 6D). However, since we did not carry out experimental validation of RASD1 p.K34M function for this study, we must caution that our claims regarding its involvement in disease biology are only hypothetical and based mainly on what is known about RASD1 biology from prior studies. Further studies should investigate the functional significance of this novel RASD1 mutation in the pathogenesis of ACTH tumors.

\section{METHODS}

\section{WES and Targeted Validation}

Paired-end ( $2 \times 100$ bp) WES on Illumina HiSeq 2500 (Illumina) and targeted amplicon validation on PacBio RSII (Pacific Biosciences) was carried as previously described (Uzilov et al. 2016), with the following modifications. For WES, the SureSelect Human All Exon V5 hybridization capture system (Agilent) was used. Libraries from three tumor and nine normal samples were multiplexed in a 2:1 tumor:normal ratio and sequenced on all eight lanes of a High Output flow cell; only two of these samples are presented in this work (others to be published in a future work).

\section{Variant Calling}

WES FASTQ files from the normal and tumor sample were combined into a patient-specific "cohort" and run through an in-house pipeline (Linderman et al. 2014) to yield binary alignment (BAM) and variant call format (VCF) files with germline and somatic variant calls (SNVs and small indels). Briefly, this in-house pipeline implements the Genome Analysis Toolkit (GATK) (McKenna et al. 2010) version 3.2, best practices for alignment, base quality recalibration, variant calling (using HaplotypeCaller), and variant quality score recalibration (VQSR) (DePristo et al. 2011; Van der Auwera et al. 2013). For read alignment, the hg19 human genome reference from UCSC (Rosenbloom et al. 2015) was used. VQSR was set to $99.5 \%$ sensitivity. Read pairs whose $5^{\prime}$ coordinates were identical were marked (except for one read pair) as duplicates by the Picard software (http://broadinstitute.github.io/ picard) and were not used for variant calling, per the above best practices, to ensure that evidence for each variant was derived from distinct DNA molecules, thus avoiding overcounting and possibly overamplified or oversampled DNA. A GATK genomic interval list was created from the design file from the WES hybridization-capture kit manufacturer; sequencing depth (Table 1) was computed only within these genomic intervals, whereas variant calling was done within these genomic intervals padded by $100 \mathrm{nt}$ on both sides. For somatic variant calling, MuTect (Cibulskis et al. 2013) (version 1.1.6-10b1ba92, HC+PON mode with default settings, using COSMIC [Forbes et al. 2015] version 68, dbSNP [Sherry 


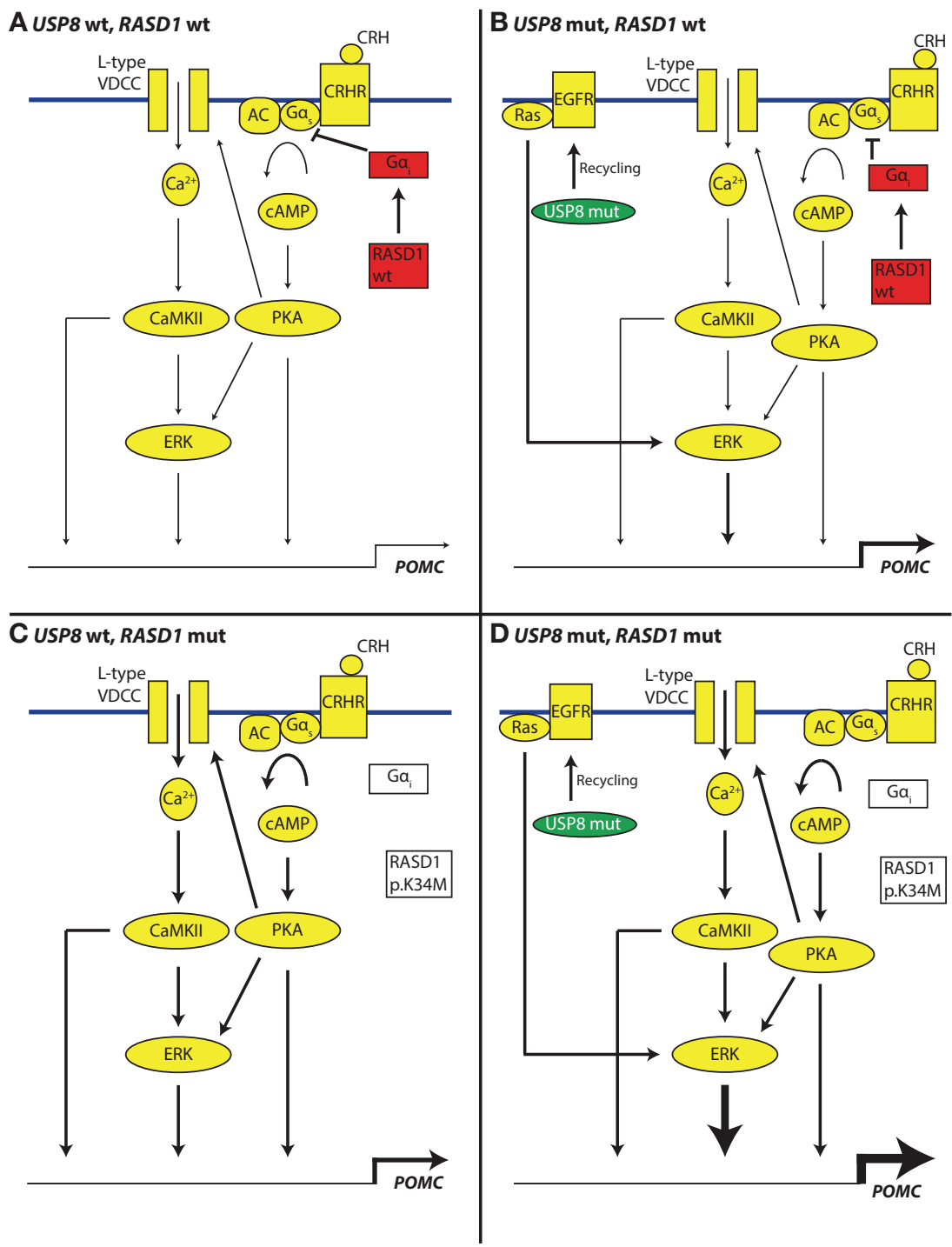

Figure 6. Hypothesized altered feedback control of the POMC gene promoter in cells having USP8 or RASD1 mutations (mut) versus wild type (wt). Contributing flux through pathway components and the effect of POMC (proopiomelanocortin gene) transcription are shown in cartoon form as small/medium/large arrow thicknesses. Pathway diagram is based on Jenks (2009). (A) Signaling through the corticotropin-releasing hormone receptor $(C R H R)$ in the context of intact feedback inhibition as indicated by active RASD1 and $G \alpha_{i}$ (red) allows for coordinated biosynthesis and secretion of ACTH. (B) USP8 mutation (green) allows for enhanced activity of the EGFR-recycling apparatus and thereby triggers stronger positive regulation of adenocorticotropic hormone $(\mathrm{ACTH})$ production. $(\mathrm{C})$ Signaling through the CRHR in the context of disrupted feedback inhibition as indicated by RASD1 and $\mathrm{Ga}_{\mathrm{i}}$ (white and disconnected from $\mathrm{Ga}_{\mathrm{s}}$ ) may allow for dysregulated and increased secretion of ACTH. (D) Signaling schematic in the context of both USP8 and RASD1 mutation, showing the possible additive or synergistic effects downstream from extracellular signal-regulated kinase (ERK). AC, adenylyl cyclase; $\mathrm{Ca}^{2+}$, calcium; CaMKII, calmodulin-dependent protein kinase II; cAMP, cyclic adenosine monophosphate; PKA, protein kinase A; VDCC, voltage-dependent calcium channel.

et al. 2001] version 138, and variant calls from patient-matched normal control as the "panel of normals" setting) and Varscan2 (Koboldt et al. 2012) (version 2.3.5, with flags -tumor-purity 0.5 and -min-var-freq 0.07 , then filtered using VS_SPVAL threshold of 20) were used. 
COLD SPRING HARBOR Molecular Case Studies
Novel RASD1 mutation in a corticotroph adenoma
SNV calls from Mutect $(N=158)$ and indel calls from Varscan2 $(N=97)$ were loaded into a custom MySQL (Percona MySOL Server Community Edition 5.6.14-rel62.0.483.rhel6) database schema using in-house scripts and annotated using RVS (Hakenberg et al. 2016) and SnpEff 4.0b (Cingolani et al. 2012) using the Ensembl (Aken et al. 2016) version 75/ GRCh37 resource bundle. Somatic calls whose population allele frequency in Exome Aggregation Consortium (ExAC) (Lek et al. 2016) exceeded 1\% were discarded on the presumption that they are any combination of contamination, a variant present but missed in the normal sample, a low-level artifact could not be pathogenic because it was too common in general population. All remaining SNV $(N=152)$ and indel $(N=64)$ calls were manually reviewed in IGV (Robinson et al. 2011; Thorvaldsdóttir et al. 2013) and the UCSC Genome Browser (Rosenbloom et al. 2015) to inspect supporting alignment quality in the BAM files and mappability of the genomic region in the hg19 human genome assembly, paying attention to whether a variant call was located in a short tandem repeat or a low-complexity sequence region (Benson 1999), a region with self-homology/duplication in the reference genome, or a region of low alignability according to the GEM track from ENCODE/CRG (Derrien et al. 2012). Uncertain calls, many of which were due to a low-level C>A substitution artifact also present in the normal or due to artifacts in padding regions, were manually rejected at this step, resulting in a final list of 25 SNV and 11 indel calls, which are shown in Figure 3, the protein-altering subset of which is shown in Table 2.

\section{Protein Sequences and Multiple Sequence Alignment}

Protein sequences are from UniProt (The UniProt Consortium et al. 2015) (retrieved 2016-0923); only human sequences selected by UniProtKB curators as canonical protein isoforms were used. HGNC gene symbols, UniProt accessions/isoform identifiers, and RefSeq accessions are as follows:

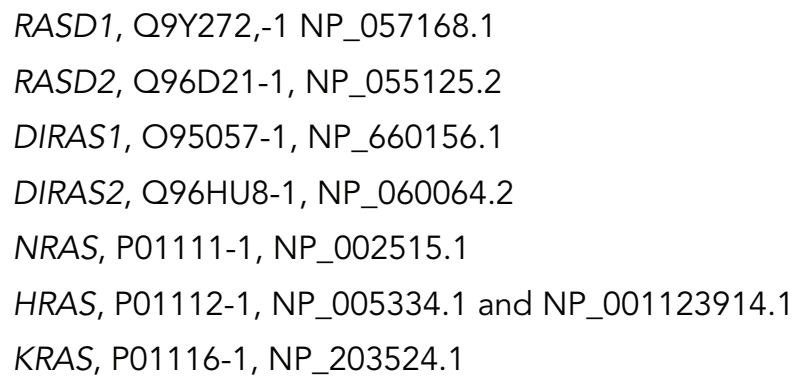

The multiple sequence alignment for Figure 4 was made using the European Molecular Biology Laboratory European Bioinformatics Institute (EMBL-EBI) Clustal Omega web tool (Goujon et al. 2010; Sievers et al. 2011) (http://www.ebi.ac.uk/Tools/msa/clustalo/, used 2016-09-24, default settings) and edited using Unipro UGENE v1.24.2 (Okonechnikov et al. 2012). Protein sequence identity of the RASD subfamily was determined by blastp of RASD1 and RASD2 against all human proteins in the RefSeq protein database (Altschul et al. 1997, 2005) (http://blast.ncbi.nlm.nih.gov, used 2016-09-25).

\section{ADDITIONAL INFORMATION}

\section{Data Deposition and Access}

All somatic mutation calls passing manual review (including those predicted to not alter protein) are provided as Supplemental File 1 and have been submitted (COSP42647) to 
COLD SPRING HARBOR Molecular Case Studies
Novel RASD1 mutation in a corticotroph adenoma
Competing Interest Statement

Y.L. is presently an employee of Novartis Pharmaceuticals Corporation. She was employed by Mount Sinai during the course of the work for this manuscript.

\section{Referees}

Masayuki Komada

Anonymous

Received November 23, 2016; accepted in revised form February 15, 2017. the COSMIC database (Forbes et al. 2015). Consent could not be obtained for public release of raw sequencing data.

\section{Ethics Statement}

The study was approved by the Institutional Review Board at the Mount Sinai Medical Center. The patient gave written informed consent before participation, including permission to publish the results.

\section{Acknowledgments}

This work was supported in part through the computational resources and staff expertise provided by the Department of Scientific Computing at the Icahn School of Medicine at Mount Sinai. We thank the Icahn School of Medicine at Mount Sinai (ISMMS) Biorepository and Pathology Core for their support. We thank Andrew F. Stewart, Azad Gucwa, and Wei Ding for helpful discussions.

\section{Author Contributions}

A.V.U., M.Y.F., C.P., and A.S.M. carried out the data processing and analysis. A.V.U., K.C.C., M.Y.F., and E.B.G. wrote the manuscript. K.C.C., Y.L., C.Y.L., M.Z., and A.G. carried out clinical and research coordination. L.C.N. and G.D. carried out the PacBio validation work. M.H. and M.F. carried out the histopathology work. Y.Ki. and M.J.D. carried out tissue processing at the ISMMS Biorepository. K.D.P. carried out surgical resection. Y.Ka., M.M., and R.S. directed the sequencing operations. D.S., E.E.S., R.S., R.C., and E.B.G. directed the study. All authors read and approved the manuscript.

\section{Funding}

This study was supported by an investigator initiated grant from Novartis Pharmaceuticals Corporation to E.B.G.

\section{REFERENCES}

Aken BL, Ayling S, Barrell D, Clarke L, Curwen V, Fairley S, Fernandez Banet J, Billis K, García Girón C Hourlier T, et al. 2016. The Ensembl gene annotation system. Database (Oxford) 2016: baw093.

Alexandrov LB, Nik-Zainal S, Wedge DC, Aparicio SA, Behjati S, Biankin AV, Bignell GR, Bolli N, Borg A, Børresen-Dale AL, et al. 2013. Signatures of mutational processes in human cancer. Nature 500: 415-421.

Altschul SF, Madden TL, Schaffer A, Zhang J, Zhang Z, Miller W, Lipman DJ. 1997. Gapped BLAST and PSIBLAST: a new generation of protein database search programs. Nucleic Acids Res 25: 3389-3402.

Altschul SF, Wootton JC, Gertz EM, Agarwala R, Morgulis A, Schäffer AA, Yu YK. 2005. Protein database searches using compositionally adjusted substitution matrices. FEBS J 272: 5101-5109.

Benson G. 1999. Tandem repeats finder: a program to analyze DNA sequences. Nucleic Acids Res 27: 573-580.

Biller BM, Alexander JM, Zervas NT, Hedley-Whyte ET, Arnold A, Klibanski A. 1992. Clonal origins of adrenocorticotropin-secreting pituitary tissue in Cushing's disease. J Clin Endocrinol Metab 75: 1303-1309.

Bourne HR, Sanders DA, McCormick F. 1991. The GTPase superfamily: conserved structure and molecular mechanism. Nature 349: 117-127.

Broder MS, Neary MP, Chang E, Cherepanov D, Ludlam WH. 2015. Incidence of Cushing's syndrome and Cushing's disease in commercially-insured patients $<65$ years old in the United States. Pituitary 18: 283-289.

Brogan MD, Behrend EN, Kemppainen RJ. 2001. Regulation of Dexras1 expression by endogenous steroids. Neuroendocrinology 74: 244-250.

Cibulskis K, Lawrence MS, Carter SL, Sivachenko A, Jaffe D, Sougnez C, Gabriel S, Meyerson M, Lander ES, Getz G. 2013. Sensitive detection of somatic point mutations in impure and heterogeneous cancer samples. Nat Biotechnol 31: 213-219. 
Cingolani P, Platts A, Wang LL, Coon M, Nguyen T, Wang L, Land SJ, Lu X, Ruden DM. 2012. A program for annotating and predicting the effects of single nucleotide polymorphisms, SnpEff: SNPs in the genome of Drosophila melanogaster strain w1118; iso-2; iso-3. Fly (Austin) 6: 80-92.

Cismowski MJ, Takesono A, Ma C, Lizano JS, Xie X, Fuernkranz H, Lanier SM, Duzic E. 1999. Genetic screens in yeast to identify mammalian nonreceptor modulators of G-protein signaling. Nat Biotechnol 17: 878-883.

Cismowski MJ, Ma C, Ribas C, Xie X, Spruyt M, Lizano JS, Lanier SM, Duzic E. 2000. Activation of heterotrimeric G-protein signaling by a Ras-related protein: implications for signal integration. J Biol Chem 275: 23421-23424.

Clayton RN, Farrell WE. 2001. Clonality of pituitary tumours: more complicated than initially envisaged? Brain Pathol 11: 313-327.

Clayton RN, Farrell WE. 2004. Pituitary tumour clonality revisited. Front Horm Res 32: 186-204.

Clayton RN, Pfeifer M, Atkinson AB, Belchetz P, Wass JA, Kyrodimou E, Vanderpump M, Simpson D, Bicknell J, Farrell WE. 2000. Different patterns of allelic loss (loss of heterozygosity) in recurrent human pituitary tumors provide evidence for multiclonal origins. Clin Cancer Res 6: 3973-3982.

Cunningham F, Moore B, Ruiz-Schultz N, Ritchie GR, Eilbeck K. 2015. Improving the Sequence Ontology terminology for genomic variant annotation. J Biomed Semantics 6: 32.

den Dunnen JT, Dalgleish R, Maglott DR, Hart RK, Greenblatt MS, McGowan-Jordan J, Roux AF, Smith T, Antonarakis SE, Taschner PE. 2016. HGVS recommendations for the description of sequence variants: 2016 update. Hum Mutat 37: 564-569.

DePristo MA, Banks E, Poplin R, Garimella KV, Maguire JR, Hartl C, Philippakis AA, del Angel G, Rivas MA, Hanna M. 2011. A framework for variation discovery and genotyping using next-generation DNA sequencing data. Nat Genet 43: 491-498.

Derrien T, Estellé J, Marco Sola S, Knowles DG, Raineri E, Guigó R, Ribeca P. 2012. Fast computation and applications of genome mappability. PLoS One 7: e30377.

Dworakowska D, Grossman AB. 2012. The molecular pathogenesis of corticotroph tumours. Eur J Clin Invest 42: 665-676.

Etxabe J, Vazquez JA. 1994. Morbidity and mortality in Cushing's disease: an epidemiological approach. Clin Endocrinol (Oxf) 40: 479-484.

Feelders RA, Pulgar SJ, Kempel A, Pereira AM. 2012. The burden of Cushing's disease: clinical and health-related quality of life aspects. Eur J Endocrinol 167: 311-326.

Feig LA, Cooper GM. 1988. Relationship among guanine nucleotide exchange, GTP hydrolysis, and transforming potential of mutated ras proteins. Mol Cell Biol 8: 2472-2478.

Forbes SA, Beare D, Gunasekaran P, Leung K, Bindal N, Boutselakis H, Ding M, Bamford S, Cole C, Ward S, et al. 2015. COSMIC: exploring the world's knowledge of somatic mutations in human cancer. Nucleic Acids Res 43: D805-D811.

Gicquel C, Le Bouc Y, Luton JP, Girard F, Bertagna X. 1992. Monoclonality of corticotroph macroadenomas in Cushing's disease. J Clin Endocrinol Metab 75: 472-475.

Goujon M, McWilliam H, Li W, Valentin F, Squizzato S, Paern J, Lopez R. 2010. A new bioinformatics analysis tools framework at EMBL-EBI. Nucleic Acids Res 38: 695-699.

Graham TE, Key TA, Kilpatrick K, Dorin RI. 2001. Dexras1/AGS-1, a steroid hormone-induced guanosine triphosphate-binding protein, inhibits $3^{\prime}, 5^{\prime}$-cyclic adenosine monophosphate-stimulated secretion in AtT-20 corticotroph cells. Endocrinology 142: 2631-2640.

Graham TE, Qiao Z, Dorin RI. 2004. Dexras1 inhibits adenylyl cyclase. Biochem Biophys Res Commun 316: 307-312.

Gray KA, Yates B, Seal RL, Wright MW, Bruford EA. 2015. Genenames.org: the HGNC resources in 2015. Nucleic Acids Res 43: D1079-D1085.

Hakenberg J, Cheng WY, Thomas P, Wang YC, Uzilov AV, Chen R. 2016. Integrating 400 million variants from 80,000 human samples with extensive annotations: towards a knowledge base to analyze disease cohorts. BMC Bioinformatics 17: 24.

Hayashi K, Inoshita N, Kawaguchi K, Ibrahim Ardisasmita A, Suzuki H, Fukuhara N, Okada M, Nishioka H, Takeuchi Y, Komada M, et al. 2016. The USP8 mutational status may predict drug susceptibility in corticotroph adenomas of Cushing's disease. Eur J Endocrinol 174: 213-226.

Herman V, Fagin J, Gonsky R, Kovacs K, Melmed S. 1990. Clonal origin of pituitary adenomas. J Clin Endocrinol Metab 71: 1427-1433.

Jenks BG. 2009. Regulation of proopiomelanocortin gene expression: an overview of the signaling cascades, transcription factors, and responsive elements involved. Ann NY Acad Sci 1163: 17-30.

Kawashima ST, Usui T, Sano T, logawa H, Hagiwara H, Tamanaha T, Tagami T, Naruse M, Hojo M, Takahashi JA, et al. 2009. P53 gene mutation in an atypical corticotroph adenoma with Cushing's disease. Clin Endocrinol (Oxf) 70: 656-657.

Kemppainen RJ. 1998. Dexamethasone rapidly induces a novel ras superfamily member-related gene in AtT20 cells. J Biol Chem 273: 3129-3131. 
Kent WJ, Sugnet CW, Furey TS, Roskin KM, Pringle TH, Zahler AM, Haussler D. 2002. The human genome browser at UCSC. Genome Res 12: 996-1006.

Koboldt DC, Zhang Q, Larson DE, Shen D, McLellan MD, Lin L, Miller CA, Mardis ER, Ding L, Wilson RK. 2012. VarScan 2: somatic mutation and copy number alteration discovery in cancer by exome sequencing. Genome Res 22: 568-576.

Lacroix A, Feelders RA, Stratakis CA, Nieman LK. 2015. Cushing's syndrome. Lancet 386: 913-927.

Landrum MJ, Lee JM, Benson M, Brown G, Chao C, Chitipiralla S, Gu B, Hart J, Hoffman D, Hoover J, et al. 2016. ClinVar: public archive of interpretations of clinically relevant variants. Nucleic Acids Res 44: D862-D868.

Lek M, Karczewski KJ, Minikel EV, Samocha KE, Banks E, Fennell T, O'Donnell-Luria AH, Ware JS, Hill AJ, Cummings BB, et al. 2016. Analysis of protein-coding genetic variation in 60,706 humans. Nature 536: 285-291.

Levy A. 2000. Is monoclonality in pituitary adenomas synonymous with neoplasia? Clin Endocrinol (Oxf) 52: 393-397.

Levy A. 2001. Monoclonality of endocrine tumours: what does it mean? Trends Endocrinol Metab 12: 301-307.

Linderman MD, Brandt T, Edelmann L, Jabado O, Kasai Y, Kornreich R, Mahajan M, Shah H, Kasarskis A, Schadt EE. 2014. Analytical validation of whole exome and whole genome sequencing for clinical applications. BMC Med Genomics 7: 20.

Lindholm J, Juul S, Jørgensen JO, Astrup J, Bjerre P, Feldt-Rasmussen U, Hagen C, Jørgensen J, Kosteljanetz M, Kristensen L, et al. 2001. Incidence and late prognosis of Cushing's syndrome: a population-based study. J Clin Endocrinol Metab 86: 117-123.

Ma Z, Song Z, Chen JH, Wang YF, Li SQ, Zhou LF, Mao Y, Li YM, Hu RG, Zhang ZY, et al. 2015. Recurrent gainof-function USP8 mutations in Cushing's disease. Cell Res 25: 306-317.

McKenna A, Hanna M, Banks E, Sivachenko A, Cibulskis K, Kernytsky A, Garimella K, Altshuler D, Gabriel S, Daly M, et al. 2010. The Genome Analysis Toolkit: a MapReduce framework for analyzing next-generation DNA sequencing data. Genome Res 20: 1297-1303.

Okonechnikov K, Golosova O, Fursov M, Varlamov A, Vaskin Y, Efremov I, Grehov G, Kandrov D, Rasputin K, Syabro M, et al. 2012. Unipro UGENE: a unified bioinformatics toolkit. Bioinformatics 28: 1166-1167.

Perez-Rivas LG, Reincke M. 2016. Genetics of Cushing's disease: an update. J Endocrinol Invest 39: 29-35.

Perez-Rivas LG, Theodoropoulou M, Ferraù F, Nusser C, Kawaguchi K, Stratakis CA, Faucz FR, Wildemberg LE, Assié G, Beschorner R, et al. 2015. The gene of the ubiquitin-specific protease 8 is frequently mutated in adenomas causing Cushing's disease. J Clin Endocrinol Metab 100: E997-E1004.

Pruitt KD, Brown GR, Hiatt SM, Thibaud-Nissen F, Astashyn A, Ermolaeva O, Farrell CM, Hart J, Landrum MJ, McGarvey KM, et al. 2014. RefSeq: an update on mammalian reference sequences. Nucleic Acids Res 42: 756-763.

Reincke M, Sbiera S, Hayakawa A, Theodoropoulou M, Osswald A, Beuschlein F, Meitinger T, MizunoYamasaki E, Kawaguchi K, Saeki Y, et al. 2015. Mutations in the deubiquitinase gene USP8 cause Cushing's disease. Nat Genet 47: 31-38.

Robinson JT, Thorvaldsdóttir H, Winckler W, Guttman M, Lander ES, Getz G, Mesirov JP. 2011. Integrative genomics viewer. Nat Biotechnol 29: 24-26.

Rosenbloom KR, Armstrong J, Barber GP, Casper J, Clawson H, Diekhans M, Dreszer TR, Fujita PA, Guruvadoo L, Haeussler M, et al. 2015. The UCSC Genome Browser database: 2015 update. Nucleic Acids Res 43: D670-D681.

Schulte HM, Oldfield EH, Allolio B, Katz DA, Berkman RA, Ali IU. 1991. Clonal composition of pituitary adenomas in patients with Cushing's disease: determination by X-Chromosome inactivation analysis. J Clin Endocrinol Metab 73: 1302-1308.

Sharma ST, Nieman LK, Feelders RA. 2015. Comorbidities in Cushing's disease. Pituitary 18: 188-194.

Sherry ST, Ward MH, Kholodov M, Baker J, Phan L, Smigielski EM, Sirotkin K. 2001. dbSNP: the NCBI database of genetic variation. Nucleic Acids Res 29: 308-311.

Sievers F, Wilm A, Dineen D, Gibson TJ, Karplus K, Li W, Lopez R, McWilliam H, Remmert M, Söding J, et al. 2011. Fast, scalable generation of high-quality protein multiple sequence alignments using Clustal Omega. Mol Syst Biol 7: 539.

Song ZJ, Reitman ZJ, Ma ZY, Chen JH, Zhang QL, Shou XF, Huang CX, Wang YF, Li SQ, Mao Y, et al. 2016. The genome-wide mutational landscape of pituitary adenomas. Cell Res 26: 1255-1259.

The UniProt Consortium; Bateman A, Martin MJ, O'Donovan C, Magrane M, Apweiler R, Alpi E, Antunes R, Arganiska J, Bely B, et al. 2015. UniProt: a hub for protein information. Nucleic Acids Res 43: D204-D212.

Thorvaldsdóttir H, Robinson JT, Mesirov JP. 2013. Integrative Genomics Viewer (IGV): high-performance genomics data visualization and exploration. Brief Bioinform 14: 178-192.

Tu Y, Wu C. 1999. Cloning, expression and characterization of a novel human Ras-related protein that is regulated by glucocorticoid hormone. Biochim Biophys Acta 1489: 452-456. 
Uzilov AV, Ding W, Fink MY, Antipin Y, Brohl AS, Davis C, Lau CY, Pandya C, Shah H, Kasai Y, et al. 2016. Development and clinical application of an integrative genomic approach to personalized cancer therapy. Genome Med 8: 62.

Vaidyanathan G, Cismowski MJ, Wang G, Vincent TS, Brown KD, Lanier SM. 2004. The Ras-related protein AGS1/RASD1 suppresses cell growth. Oncogene 23: 5858-5863.

Van der Auwera GA, Carneiro MO, Hartl C, Poplin R, Del Angel G, Levy-Moonshine A, Jordan T, Shakir K, Roazen D, Thibault J, et al. 2013. From FastQ data to high confidence variant calls: the Genome Analysis Toolkit best practices pipeline. Curr Protoc Bioinformatics 43: 11.10.1-11.10.33.

Wennerberg K, Rossman KL, Der CJ. 2005. The Ras superfamily at a glance. J Cell Sci 118: 843-846.

Zhang Z, Hao K. 2015. SAAS-CNV: a joint segmentation approach on aggregated and allele specific signals for the identification of somatic copy number alterations with next-generation sequencing data. PLoS Comput Biol 11: 1-27. 


\section{COLD SPRING HARBOR Molecular Case Studies}

\section{Identification of a novel RASD1 somatic mutation in a USP8 -mutated corticotroph adenoma}

Andrew V. Uzilov, Khadeen C. Cheesman, Marc Y. Fink, et al.

Cold Spring Harb Mol Case Stud 2017, 3: a001602 originally published online March 3, 2017 Access the most recent version at doi: $10.1101 / \mathrm{mcs} . a 001602$
Supplementary http://molecularcasestudies.cshlp.org/content/suppl/2017/03/03/mcs.a001602.D Material C1
References This article cites 67 articles, 10 of which can be accessed free at: http://molecularcasestudies.cshlp.org/content/3/3/a001602.full.html\#ref-list-1
License This article is distributed under the terms of the Creative Commons Attribution License, which permits unrestricted reuse and redistribution provided that the original author and source are credited.
Email Alerting Receive free email alerts when new articles cite this article - sign up in the box at the Service top right corner of the article or click here.

